\title{
Social networks as an educational resource
}

\author{
Olga Tomyuk ${ }^{1}$, Margarita Dyachkova², Anna Shutaleva ${ }^{1, *}$, Alexey Fayustov ${ }^{1}$, Evgenia Leonenko ${ }^{1}$ \\ ${ }^{1}$ Ural Federal University named after the first President of Russia B.N. Yeltsin, 620075, Ekaterinburg, Russian Federation. \\ ${ }^{2}$ Ural State Pedagogical University, Ekaterinburg, 620017, Russian Federation.
}

\begin{abstract}
The article deals with the problem of the use of social networks as an educational resource as a necessary aid for learning. Interest in this problem is caused by a high degree of involvement in the information space through social networks of precisely young people. The purpose of this article is to examine the problem of directly applying popular social networks in the educational process of a university. The subject of the study is social networks and their capabilities as an educational resource. The article based on the analysis of the research results revealed an educational resource of social networks. The educational resource of social networks consists of the fact that various programs and projects are being implemented through social networks, including individual trajectories of development of students based on individual educational programs. The inclusion of social networks in the educational process provides a wide popularization of cultural and national traditions, the involvement of students in creative activities, the creation of conditions for their self-education, career development. The authors of the article explore the possibilities of using modern educational technologies when social networks are included in the educational process on the examples of debates, social design, a forum, and new information technologies. In order to engage students in a virtual educational environment, a coordinator is needed, who has the necessary competencies, who own effective methods for carrying out this type of activity. The authors of the article justify the need for the direct use of social resources on the Internet in education.
\end{abstract}

\section{Introduction}

Digital technologies penetrate dynamically into all educational processes and, thus, change the essence of education. As practice shows, the expanding use of new information and communication technologies leads to the development of educational technologies, effective practices, and successful projects. The most critical tasks of higher education are the updating of its content by the capabilities of information and communication technologies, the training of students in individual educational programs, including independent work using information and communication technologies.

The systematic use of information and communication technologies and tools forms a growing interest in the educational environment to explore the possibilities of using information resources, in particular, social networks. Therefore, the active involvement in the educational process of new communication channels, namely social networks, designed to establish connections, relationships between people, and expand their circle of contacts is relevant.

The purpose of this article is to identify the possibilities of social networks in terms of using them as a university educational resource.

Networks are quite old and well-known forms of organization of human activity, the essence of which consists in organizing a multitude of interconnected chains intersecting in certain nodes-points of information flows and actors of information interaction. M. Castells describes a complex of interconnected nodes-points of information flows and actors of information interaction as a network community [1]. V. Benjamin emphasizes the role of the visual aspect of people's communication [2]. G. Debord considers the structure of the societyperformance produced by mass media [3]. W. Eco calls modern civilization a civilization of vision. U. Eco emphasizes the leading role of visual communication as the ability of an iconic sign to reflect reality not directly and realistically, but through multiple interpretations [4].

The development and introduction of advanced network services are associated with the development of Internet space and, as a result, the growth of the Internet audience included in the network interaction. The creation of computer technology and the emergence of the Internet made it possible to develop a global communication network. The Internet initially conceived for computer communications, began to establish interactions in the "person-to-person" system through technical means $[5 ; 6 ; 7]$. Social networks have become a new type of communication of modern man $[8 ; 9 ; 10]$ and his evolution $[11 ; 12]$. Therefore, social networks are in the research field of different sciences, namely, psychology, pedagogy, sociology, computer science.

A social network is an Internet site whose visitors have the opportunity to create an information resource in order to establish connections with people who share their interests. In the created information resource, the

* Corresponding author: a.v.shutaleva@urfu.ru 
user can present information about himself, his interests, and his achievements. Social network users themselves can create custom content. It does not require any additional funds, such as instant messengers or e-mail.

Actual issues today are the problems of practical use of social networks for communication of people in everyday and educational space. However, in the works related to the study of social networks, the focus is mainly on studying the dependence of modern men on social networks, the risks of virtual interaction. The inclusion of social networks in the educational process will enhance the quality of education, strengthen the motivational component in learning.

\section{Materials and methods}

The subject of research in this article is the possibilities of social networks as an educational resource, their integration into modern university education. Studies that draw attention to the identification of training and educational opportunities of social networks, the search for ways to integrate social networks in solving educational problems, in general, are used.

The following theoretical and methodological principles are the methodological basis for the study of social networks as an educational resource.

First, understanding the specifics of social networks as a resource with an emerging own status system through the creation of its own culture, revealed through language, norms, and traditions.

Secondly, the difference in the methodological principles of contact and contextual social networks, which determines the nature of the participants' interaction, self-presentation, and identity.

Thirdly, the understanding of social networks as a phenomenon of everyday life, based on the study of everyday life and the multiplicity of realities of the world in the framework of the phenomenological approach developed by A. Schütz [13; 14].

Fourthly, the understanding of the communicative nature of social space was revealed in the works of $\mathrm{J}$. Habermas [15; 16], E. Giddens [17], M. Castells [1].

Fifth, an understanding of the role of the visual aspect of human communication in modern society $[2 ; 3$; 4].

Sixth, in practical experience, methods create a productive, communicative environment between the teacher and students $[18 ; 19 ; 20]$, where the psychological aspect is essential $[21 ; 22]$.

Seventh, the experience of applying methods and tools for analyzing social networks and the method of dynamic analysis of social networks [23].

\section{Results}

The superior experience in the use of educational innovations, the introduction of new educational technologies, the scientific and methodological base of the Ural Federal University named after the first President of Russia BN Yeltsin (after this referred to as the Ural Federal University) corresponded to the objectives of the project.

For the implementation of student projects through social networks in the Ural Federal University, there are several advantages:

- teachers who have the training necessary for the implementation of educational projects through social networks;

the readiness of teachers and students of the university to introduce innovations, improve their knowledge and skills, and gain experience in project activities using a modern resource;

the system of social partnership with scientific, cultural, and educational organizations that have developed at the Ural Federal University.

Opportunities The Ural Federal University can be viewed as a resource for providing and scientificallymethodical support for student projects of various kinds through social networks.

Thus, as part of the implementation of project activities, students of the training direction - 42.03.05 "Media Communications" (undergraduate level) together with teachers of the Ural Federal University implemented a number of projects through social networks, for example, the XXIX Open Documentary Film Festival "RUSSIA", 2018", International forum on cognitive neuroscience "COGNITIVE NEUROSCIENCE".

The XXIX Open Documentary Film Festival "RUSSIA" (Yekaterinburg, October 1-7, 2018) is a film festival held since 1988 in Sverdlovsk (later Yekaterinburg), which includes documentaries and popular science films. The Open Documentary Film Festival "RUSSIA" is one of the oldest documentary film shows, which annually shows the complete picture of the life of a multinational, multicultural society. In the rating of 76 domestic and international film festivals held in Russia and on the territory of the former USSR, the documentary film festival RUSSIA ranks third, second only to Kinotavr and the Moscow International Film Festival.

Students of the training direction implemented administrative work with festival accounts on social networks Instagram, Vkontakte, and Facebook, production, display, and reading of content, its coordination and design - 42.03.05 "Media Communications" (undergraduate level) under the guidance of university professors and specialists of the Media Center of the Ural Federal University .

During the implementation of the project to support the festival "RUSSIA," the festival's page was created on the Instagram social network, where 76 subscribers, mostly young people, were attracted. The audience reach on the social network VKontakte was 10,300 people, and during the announcement of the festival's events, the Sverdlovsk Regional Universal Scientific Library named after Belinsky, the cultural institution "Multimedia Historical Park "Russia - My Story," Public Library (Novouralsk).

"KHOROVOD" - an event held on the birthday of the university and gathering all students in a large round dance. The goal of "KHOROVOD" is to acquaint 
students with the traditions of the Ural Federal University, the unification of university students, and the development of student self-government. "KHOROVOD -2018 " also envisaged the project activity of students in the area of training - 42.03.05 "Media Communications" (bachelor's level), which was supervised by teachers of the journalism department and heads of the information department of the Students Union of the Ural Federal University. The project group was engaged in the production of media content, interaction with the target audience through the social network VKontakte. During the work of the project team and the announcement of the action, subscribers registered an increase of 2,290 people, the number of views was 20,600 (the highest since 2014), the coverage for the event group was 32,300 people, the page visit was 5,800 unique users (the highest over the past three years).

The Ural Federal University organized the International Forum on Cognitive Neuroscience "COGNITIVE NEUROSCIENCE - 2018" (Ekaterinburg, 6-8.11.2018) in cooperation with the Ural State Medical University with the support of the industry union "Neuronet." The purpose of the forum is to combine the experience of leading experts in the field of cognitive neuroscience, to determine the development prospects of modern neuroscience. Within the framework of the forum, project work was carried out for students and teachers of the "Media Communication" training area.

The project provided for the implementation of administrative work in the social network VKontakte: production, coordination, design, the publication of media content on the topics of the forum. As a result of the work of the project team during the announcement and holding of the forum, the audience reach in the social network was 3,000, with an average attendance of about 400 people per month. With the help of content, it was possible to popularize the topic of cognitive neuroscience, to acquaint the audience with Russian and international research in this scientific field.

During the study, we surveyed teachers and students to identify the degree of their involvement in social networks, specifically for educational purposes (Ural Federal University, February - March 2019).

Procedures for collecting and analyzing source data: - questionnaire "The role of the social network "VKontakte" in my life" for teachers and students of the Ural Federal University;

the questionnaire "The possibilities of using the social network" VKontakte "in the project work" students of the Ural Federal University;

- online-interview of teachers and students of the Ural Federal University "Project in the social network" VKontakte: "Advantages and disadvantages."

An analysis of the data showed that $96 \%$ of university students surveyed saw on social networks Vk.ru, Facebook.com, Ok.ru, Twitter.com great opportunities for learning: communication in the community of friends, fellow students, a safe space, the possibility of collaboration (forums, webinars, chats), electronic notebooks, information sharing. More than $40 \%$ of university professors indicated that they use social networking resources to work with students when studying academic disciplines. Working in social networks, according to university professors, has such advantages as the speed of disseminating the necessary information, openness and accessibility of educational content, the ability to create groups "student-student," "teacher-students." The examples were named vk.com/english, vk.com/podslushanodebatyschool.

Let us give some opinions of students about the possibilities of social networks as an educational resource. According to students, the ability to work in social networks is essential in professional activities; social networks should be used as widely as possible in the practice of university education, in organizing interactive interaction. Students note that learning through social networks is exciting and exciting; they can get an education by building an individual learning path.

Thus, the results of a survey of teachers and students to identify the degree of their involvement in social networks for educational purposes confirmed the need to include social networks in the educational process of a modern university.

The involvement of young people in communication through social networks indicates the presence of such necessary starting opportunities for organizing students' project work using social networks, such as:

the possibility of interpersonal and intercultural interaction;

the possibility of dynamic, mobile teamwork;

the possibility of mastering new ways of selforganization and self-education;

the possibility of mastering the technology of project work using social networks;

improvement of information and communication competence;

the possibility of developing additional motivation for higher education.

As a result of our research, we identified some problems associated with the use of social networks as an educational resource. Let us name the most significant of them: the level of proficiency of information and communication competencies of university teachers does not fully meet modern requirements, limited access to social networks in the territory of an educational organization, and, importantly, considerable time spent by teachers on providing an educational process through social networks.

In our opinion, social networks should be considered as a tool for designing and implementing an educational process, a necessary educational resource at different levels of higher education. Creating a piece of information and educational environment through social networks is the reality of a modern university.

Another important conclusion: social networks are more connected to meet the needs of entertainment. However, social networks form a unique culture, where in order to engage students in an educational environment using social networks, a coordinator is needed - a university teacher who has the necessary 
competencies and has effective techniques for integrating virtual social resources into education.

\section{Discussion}

The process of communication passes through various channels; it involves verbal and non-verbal communication tools. Communication has specific goals: the exchange and transfer of information, the exchange of innovative techniques, tools, technologies, values. Mass communications are a complex system of interaction in the extraction and transfer of meanings, the implementation of which becomes possible because technologies are updated continuously and complicated [22; 24; 25].

The provision of global communication became possible due to the development of information technologies and the creation of social networks on their basis. Social networks have a service on the Internet, thanks to which users have the opportunity to establish connections with other users, to create a personalized standardized virtual page. Social networks have the characteristic features of a network community, ICQ, forum, which allows the user to create a personal network of relationships with different people to discuss, solve problems that concern them.

It should be noted that social networks perform the most important functions for a modern person [26; 27]:

- communication (communication in order to exchange information, maintain, strengthen ties);

socializing (assimilation and adoption of cultural norms and social experience necessary for functioning in society);

information (receiving / disseminating

information);

self-actualization (satisfaction of human needs in the implementation of internal potential);

identification (I-positioning in the virtual social community);

educational (receiving / distribution / use of information for educational purposes);

- entertaining, leisure.

Social networks, because of their features, are attractive to a wide range of users. Features of social networks and communication in social networks:

disembodiedness (communication of virtual images devoid of physicality),

anonymity (a virtual image of a real person),

- lack of spatial attachment, communication of people who are in a significant territorial distance from each other,

temporary asynchronous communication, limited forms of self-expression (symbols, emoticons),

communication without low barriers, evaluation of partners in communication interaction on the content of the interaction.

Thus, communication through social networks is a new type of communication that has arisen due to the transition of the global network to the second stage of development - Web 2.0. According to T. O'Reilly, users are not just passive consumers of information, but they create and distribute content [28].

Modern social networks make it possible to spread information to a mass audience through telecommunications. Communities and social media pages as social media are a combination of network technologies that allow users to freely share information and carry out social communication [19].

It should be noted that social media as a means of online communication (Internet communities, blogs, collaborative projects, geosocial services) become social only when they are in communication. Otherwise, it is the traditional media tools.

As practice shows, social networks are actively used as a way to promote a business. The social networking sites of Instagram.com, Twitter.com, Facebook.com, Vk.ru provide a unique opportunity to create corporate communities, to interact in order to solve a wide range of problems. According to experts, Facebook.com is the largest social network in the world, as the number of users of this network exceeds 1 billion people. Facebook.com has the necessary resources for organizing a community of students in a class, a student group for constant communication.

According to the results of research conducted by the Public Opinion Foundation (after this - FOM), Russian citizens are active users of social networks. According to the FOM, popular social networks are [29]):

Facebook.com is a foreign social network with a wide range of topics (there is an interface in Russian); audience -21 million people;

Vk.ru - domestic all-thematic network; audience 46 million people;

- Ok.ru is a domestic network with a variety of topics; the audience is 31 million people;

- Instagram.com is a foreign network; the audience is 12 million people;

- Twitter.com - a foreign network that has resources for instant messaging; audience -6 million people;

- My.mail.ru is a national network, where somebody can exchange information, create content, communicate; audience - 16 million people

The standard of behavior of a modern person is the daily use of Internet resources in everyday life, educational and professional activities. As a result, the development of a virtual network and the expansion of the audience of users led to the emergence of new social roles - a member of the Internet community, a user, a member of the network community.

Given the active involvement of young people in network communication, it is necessary to consider social networks as a possible educational resource, through which they can solve not only education and information but also training and education.

In our opinion, the educational resource of social networks consists in the possibility of using them in a wide range: to popularize the achievements of science, to implement projects, to carry out project work with students at all levels of higher education, and more.

Since the youth is an active user of such social networks as Vk.ru, Facebook.com, Ok.ru, Twitter.com, it 
is their resources that should be actively involved in education.

The organization of the educational process in social networks makes it possible to use modern educational technologies. These include the following technologies:

debates, which, as a technology of persuasion, are aimed at developing confidence, the conviction in their position, ability to influence the opinion of the participants of the social community;

the technology of social and pedagogical design, the mastering of which is necessary for achieving a socially approved and personally significant goal;

- technology "civil forum" aimed at attracting students to discuss socially significant problems, analyze approaches to solving a socially significant problem when their joint actions are needed;

gaming technology aimed at shaping the style and language of communication.

An important direction of work with university students through social networks is the development of the ability to identify and build promising lifelines, possible applications of their forces. In this context, the technology of organizing the volunteer movement makes sense.

New information technologies should be mentioned, for example, "Active Citizen," "Electronic Reception," which can also be used in work through social networks. The pedagogical potential has, in our opinion, the technology of "crowdsourcing," the essence of which consists in attracting to the solution of topical issues, often of an innovative nature, the most significant possible number of users with creative potential.

Using crowdfunding technology in social networks, people can unite different people in order to provide support, help people in need, those who find themselves in a difficult life situation.

The technologies mentioned above as pedagogical tools make it possible to track current socially significant projects and involve students for their development. Qualitative monitoring of the assessment of the significance of social projects is possible thanks to social networks, which have a wide range of tools for identifying ratings, forming communities, interested user groups, and evaluating.

Gamification (gamification) is another innovation of the virtual space, involving the use of game thinking with mandatory feedback in order to activate the audience to solve problems. It is known that any work can be presented in a game form, which ensures an increased interest, a quick immersion into the problem and the achievement of an optimal result. Motivation is supported by changing the rules of the game, the introduction of new game elements.

In our opinion, gamification technology has many competitive advantages compared to other innovative technologies. Benefits include dynamism, the ability to use different scenarios, a wide range of incentive elements (rewards, statuses, points, emoticons), aesthetic component, game experience, emotional involvement, social interaction using a wide range of techniques, for games.
Consider the possibility of a blog as a weblog, where people can continuously update all components of information (multimedia, images) through mobile devices. If blogs are used in the educational process, this will allow not only sharing information but also with the group of students to perform tasks, exchange ideas, comment on messages and much more. For a teacher, a training blog is a resource that allows us to design educational communications, manage students' independent work, and share opinions about an educational event.

The focus of education on individualization leads to understanding of social networks as the particular relevant phenomenon, because they give another opportunity to develop and maintain an individual educational program, building an individual educational trajectory.

In the individualization of education, such resources as Internet libraries, training sites, special training computer programs, games, webinars, and video lectures are of exceptional importance. All these resources are a prerequisite for distance education, which expands the possibilities of professional education, pre-vocational training, vocational education, and career development. Design and implementation of the educational process through social networks contribute not only to building individual educational routes for students but also to the formation of a wide range of competencies; they are a useful motivational component of cognitive activity.

In social networks, people can work in offline programs, youth clusters (educational tourism, professions), organize and conduct seminars, discussions, educational events, which makes networks a useful learning tool. Specialized social networks vmesti.ru, scribbler.ru, organized by the Learning Management System (LMS), are endowed with learning management resources, make the learning process more accessible to a wide range of users. Accessibility and individualization of education are ensured by the unified educational network - www.dnevnik.ru.

Social networks organically fit into the project activity, allow combining as participants students, professionals living remotely from the venue of the event. Moreover, this is another significant educational resource for social networks.

\section{Conclusion}

The use of resources of social networks in the educational space has many advantages that are related to the fact that social networks are a familiar communication medium for students, as well as a variety of forms of communication that provide ample opportunities for collaboration. Educational services assume an unambiguous identification of users because in electronic scientific and educational resources and networks a person is registered under his name and surname, in other Internet services; on the contrary, he can choose a pseudonym and hide his identity.

Educational services and social networks allow students to be able to keep abreast of all changes 
occurring in the process of learning activities, to monitor the educational activities of classmates and teachers, whose task is to monitor and coordinate the work of students. However, in order for social networks to become a full-fledged educational environment in the educational space, it is necessary to overcome many difficulties and problems of various kinds that require the joint work of information technology specialists and teachers.

\section{References}

1. M. Castells, The Information Age: Economy, Society and Culture Volume 1: The Rise of the Network Society. 2nd ed. (Oxford: Wiley Blackwell, 2010)

2. W. Benjamin, Selected Writings, 2, 1. (Cambridge, 2005)

3. G. Debord, The Society of the Spectacle. Translation by Donald Nicholson-Smith. New York: Zone Books (1994)

4. U. Eco, Interpretation and Overinterpretation. (Cambridge University Press, 1992)

5. R. van der Merwe, L. Pitt, P. Berthon, EMJ, The strategic Elusive Ensembles, 22(1), 12-26 (2004)

6. M.E. Kudryavtseva, M.B.Rotanova, Proceedings of the 2018 IEEE Communication Strategies in Digital Society Workshop, ComSDS 2018, The problem of sense creation in interpersonal communication of youth in the digital age, 33-35 (2018)

7. L.V. Baeva, The Changing Scope of Technoethics in Contemporary Society, IGI Global, Communication in the E-culture and media: New trends and features (Book Chapter), 327-342 (2018)

8. N.Aghakhani, J.Karimi, M.Salehan, IJEC, A Unified Model for the Adoption of Electronic Word of Mouth on Social Network Sites: Facebook as the Exemplar, 22(2), 202-231 (2018)

9. A.I. Matveeva, Research transfer Materials of the International Conference. Minzu University of China, The role of "human wealth" in assessing entrepreneurship, as a social and legal group, 20-27 (2018)

10. A.I. Matveeva, A.V. Sarapultseva, Components of Scientific and Technological Progress, Institutional prerequisites of the system of social partnership: philosophical and economic aspects, 4(30), 29-31 (2016)

11. C. Bertoncello, M. Colucci, T. Baldovin, A. Buja, V. Baldo, PLoS ONE, How does it work? Factors involved in telemedicine home-interventions effectiveness: A review of reviews, 13(11), e0207332 (2018)

12. A. Shutaleva, E. Ivanova, E. Mel'nikova, O. Tomyuk, O. Kuznetsova, INTED2017: 11th international technology, education and development conference. (INTED Proceedings), Mass culture as a challenge to modern education, 3914-3922 (2017)
13. A. Schütz, The Theory of Social Action: The Correspondence of Alfred Schutz and Talcott Parsons. Bloomington: Indiana University Press (1978)

14. A. Schütz, Life forms and meaning structure. (London: Routledge \& K. Paul, 1982)

15. J. Habermas, Theory of Communicative Action, Volume One: Reason and the Rationalization of Society. (Boston, Mass.: Beacon Press, 1984)

16. J. Habermas, Theory of Communicative Action, Volume Two: Lifeworld and System. (Boston, Mass.: Beacon Press, 1987)

17. A. Giddens, Runaway World: How Globalization is Reshaping Our Lives. (London: Profile, 1999)

18. K. Vela, JMLA, Using slack to communicate with medical students, 106(4), 504-507 (2018)

19. M.Á. Peña Hita, E. Rueda López, M.d.C. Pegalajar Palomino, Pixel-Bit, Revista de Medios y Educacion, Posibilities of teaching networks in skills development higher education: Students's perceptions 53, 239-252 (2018)

20. E. Symanyuk, A. Pecherkina, INTED2017: 11th international technology, education and development conference (INTED Proceedings), Copsychological characteristics of perfectionism in university teaching staff, 3934-3941 (2017)

21. E. Symanyuk, A. Pecherkina, New Educational Review, A study on the components of teachers' professional competence, 44(2), 198-210 (2016)

22. M. Matsiola, P. Spiliopoulos, R. Kotsakis, C. Nicolaou, A. Podara, Education Sciences, Technology-enhanced learning in audiovisual education: The case of radio journalism course design, 9(1), 62 (2019)

23. S.L. Toral, M.R. Matiner-Torres, F. Barrero, J.UCS, Modelling Mailing List Behavior in Open Source Projects: the Case of ARM Embedded Linux, 15(3), 648-664 (2009)

24. C. Mejía, Y. Kajikawa, Technological Forecasting and Social Change, Technology news and their linkage to production of knowledge in robotics research, 143, 114-124 (2019)

25. D.A. Alsaleh, M.T. Elliott, F.Q. Fu, R. Thakur, JRIM, Cross-cultural differences in the adoption of social media, 13(1), 119-140 (2019)

26. A.S. Zotova, V.V. Mantulenko, N.A. Timoshchuk, L. Stašová, Advances in Intelligent Systems and Computing, Information and education means of social educational networks, 908, 494-501. (2020)

27. L. Atzori, C. Campolo, B. Da, R., Girau, A. Iera, G. Morabito, S. Quattropani, Future Generation Computer Systems, Smart devices in the social loops: Criteria and algorithms for the creation of the social links, 97, 327-339 (2019)

28. T. Reilly, What is Web 2.0?', Retrieved from: http://www.oreillynet.com/pub/a/oreilly/tim/news/20 05/09/ 30/what-is-web-20.html (2005) 
29. Public Opinion Foundation, Retrieved from: https://fom.ru/ (2019) 